\title{
(2) OPEN ACCESS \\ Towards better evidence-informed global action: lessons learnt from the Lancet series and recent developments in physical activity and public health
}

\author{
Ding Ding (1) , ${ }^{1,2}$ Andrea Ramirez Varela, ${ }^{3}$ Adrian E Bauman, ${ }^{1,2}$ Ulf Ekelund ${ }^{4}$ \\ I-Min Lee, ${ }^{5,6}$ Gregory Heath, ${ }^{7}$ Peter T Katzmarzyk, ${ }^{8}$ Rodrigo Reis, ${ }^{9,10}$ Michael Pratt
}

- Additional material is published online only. To view, please visit the journal online (http://dx.doi.org/10.1136/ bjsports-2019-101001)

For numbered affiliations see end of article.

Correspondence to Dr Ding Ding, Prevention Research Collaboration, School of Public Health, The University of Sydney, Sydney, NSW 2006, Australia;

melody.ding@sydney.edu.au

Accepted 3 September 2019 Published Online First 27 September 2019

\section{Check for updates}

(C) Author(s) (or their employer(s)) 2020. Re-use permitted under CC BY-NC. No commercial re-use. See rights and permissions. Published by BMJ.

To cite: Ding D, Ramirez

Varela A, Bauman AE,

et al. Br J Sports Med

2020:54:462-468.

\section{ABSTRACT}

In the past few decades, the field of physical activity has grown and evolved in scope, depth, visibility and impact around the world. Global progress has been observed in research and practice in physical activity regarding surveillance, health outcomes, correlates/determinants, interventions, translation and policy. The 2012 and 2016 Lancet series on physical activity provide some of the most comprehensive global analysis on various topics within physical activity. Based on the Lancet series and other key developments in the field, literature searches, and expert group meetings and consultation, we provide a global summary on the progress of, gaps in and future directions for physical activity research in the following areas: (1) surveillance and trends, (2) correlates and determinants, (3) health outcomes and (4) interventions, programmes and policies. Besides lessons learnt within each specific area, several recommendations are shared across areas of research, including improvement in measurement, applying a global perspective with a growing emphasis on low-income and middle-income countries, improving inclusiveness and equity in research, making translation an integral part of research for real-world impact, taking an 'upstream' public health approach, and working across disciplines and sectors to co-design research and co-create solutions. We have summarised lessons learnt and recommendations for future research as 'roadmaps' in progress to encourage moving the field of physical activity towards achieving population-level impact globally.

\section{INTRODUCTION}

Worldwide, more than 1.4 billion adults do not get recommended levels of physical activity and are, therefore, at risk of developing physical inactivityrelated non-communicable diseases (NCDs). ${ }^{1}$ The global pandemic of physical inactivity ${ }^{2}$ is responsible for more than 5 million deaths ${ }^{3}$ and at least $\$ 67.5$ billion of economic burden per year. ${ }^{4}$ Since some of the earliest epidemiological evidence on the health benefits of physical activity published in the $1950 \mathrm{~s},{ }^{5}$ the research field has evolved substantially in scope, depth, visibility and impact, evidenced by the growing number of researchers, publications, research centres, projects, initiatives and policies. Progress has been observed in global physical activity surveillance, research on the health consequences, and correlates and determinants of physical inactivity, interventions, translation and policy. ${ }^{6}$
Significant publications in the field include the 2012 (https://www.thelancet.com/series/physicalactivity) and 2016 (https://www.thelancet.com/ series/physical-activity-2016) Lancet series on physical activity, authored by an international group of experts on various physical activity topics within the global health context. These two Lancet series have been highly visible in the field, with more than 16000 citations since publication (as of 30 July 2019, Google Scholar). In June 2018, with support from the National Cancer Institute, the University of California San Diego Institute for Public Health hosted a series of public lectures and expert group meetings to discuss the lessons learnt from the Lancet series, current research gaps and directions for future research on physical activity and public health. Stemming from the discussion on the Lancet series and other key developments in the field, such as the US 2018 Physical Activity Guidelines Advisory Committee (PAGAC) Scientific Report ${ }^{7}$ and the 2018 WHO Global Action Plan for Physical Activity (GAPPA), ${ }^{8}$ supplemented by further consultation with experts (the 2012 and 2016 Lancet physical activity series steering committees and lead authors on each series paper) and literature searches, herein we provide our reflections on the progress of physical activity and global public health research in the following areas: (1) surveillance and trends, (2) correlates and determinants, (3) health outcomes and (4) interventions, programmes and policies.

\section{SURVEILLANCE AND TRENDS}

The progress in global physical activity surveillance is evidenced by the marked increase in the number of countries with physical activity surveillance. ${ }^{9}{ }^{10}$ Early physical activity surveillance efforts were concentrated in a small number of high-income and upper-middle-income countries. In the last two decades, the development of the International Physical Activity Questionnaire ${ }^{11}$ and the Global Physical Activity Questionnaire ${ }^{12}$ has enabled standardised physical activity surveillance and comparative assessment of physical activity levels across countries and over time. Through the WHO STEPwise approach to chronic disease risk Surveillance initiative, many countries now have ongoing physical activity surveillance data collection. The number of countries with national adult physical activity prevalence data was 122 in 2008 (89\% population coverage), ${ }^{10} 146$ in $2010(93 \%)^{9}$ and 168 in 2016 (96\%). ${ }^{1}$ Meanwhile, the number 
of countries with adolescent surveillance data has increased from $105(68 \% \text { population coverage })^{10}$ to $120(76 \%) .^{9}$

Ongoing physical activity surveillance allows for trend assessment in countries with multiple data collections, for example, for adult physical activity surveillance, 65 countries had prevalence data for more than one time point. ${ }^{1}$ However, the caveat is that the evolution of physical activity guidelines ${ }^{713} 14$ has resulted in a change in the definition of 'physical inactivity' in surveillance. Specifically, when the definition of physical inactivity changed from failing to meet the previous recommendations $(30 \mathrm{~min}$ of moderate-intensity physical activity on at least 5 days per week, or $20 \mathrm{~min}$ of vigorous physical activity on at least 3 days per week, or a combination of walking, moderate-intensity or vigorousintensity activities, totally 600 MET minutes per week) ${ }^{13}$ to the current recommendations (at least $150 \mathrm{~min}$ of moderate-tovigorous-intensity physical activity per week regardless of over how many days activity is accumulated), ${ }^{71}$ there seems to be an artificial decline in the global prevalence of physical inactivity. ${ }^{9}{ }^{10}$ However, after standardising all prevalence estimates to the current recommendations format, there is little evidence for substantial improvements in meeting recommended physical activity levels globally. ${ }^{1}$

Reliable and valid measurement is essential to surveillance. Despite the well-documented limitations of self-reported physical activity, ${ }^{15} 16$ global estimates of physical activity prevalence and trends currently rely primarily on self-reported physical activity. For example, the WHO target to reduce physical inactivity by $10 \%$ globally by 2025 and $15 \%$ by 2030 will be evaluated based on self-reported physical activity data, which will differ substantially from the prevalence estimated based on devices. ${ }^{17}$ While incorporating device-based measures (eg, accelerometers) into physical activity surveillance has been proposed as an important step forward, ${ }^{8} 10$ these methods measure different constructs of physical activity compared with self-report. To date, a few highincome countries (Canada, England, Norway, Portugal, Sweden and the USA) have implemented device-based methods of physical activity assessment in surveillance systems. ${ }^{18-20}$ Meanwhile, the feasibility of standardised data collection by accelerometers in large population-based samples in middle-income countries has been demonstrated in multinational research studies. $^{21} 22$ However, advancing from single cross-sectional studies to ongoing surveillance remains a challenge.

Perhaps an even greater challenge is that the estimates derived from these studies varied substantially as a result of different data collection, processing and analysis protocols. Thus, to expand the current usage of device-based methods, such as accelerometry or pedometry, from research studies among selected samples to population-level surveillance systems, standardisation of data collection methods, data processing and analysis is needed. ${ }^{9}{ }^{19}$ Public repositories of raw accelerometry data in vectors from surveillance studies offer promise in this standardisation. ${ }^{23}$ Continued monitoring of physical activity by self-report in surveillance systems in combination with devicebased assessments where and when feasible is likely the optimal approach to further expand our knowledge on global levels and trends in physical activity. However, successful implementation of comparable device-based measures of physical activity in surveillance systems requires a universal consensus on methodology, including monitor placement, data cleaning and reduction. Unfortunately, this is not always the case in those few countries that have implemented device-based measures in their surveillance systems.

Another promising area for surveillance is using mobile phones as a tool to study human behaviours at the population level. Althoff et al used data from Apple iPhones with built-in accelerometers to measure physical activity of 717527 people across 111 countries. ${ }^{24}$ Given the omnipresence of smartphone ownership $^{25}$ and the validity of inbuilt accelerometers, ${ }^{26} 27$ smartphones present great potential for physical activity surveillance. However, methodological and practical challenges (eg, how and when a smartphone is carried in real-living environments, ${ }^{28}$ complications around data ownership and control and its related privacy, ethical and legal issues ${ }^{29}{ }^{30}$ ) need to be overcome before smartphone-based physical activity measurement could be applied to population surveillance.

It is important to acknowledge that the current global physical activity surveillance system is mostly limited to minutes of aerobic moderate-to-vigorous physical activity (MVPA), which is a key, but not sole component of the current physical activity guidelines. ${ }^{7} 14$ To date, few countries included the muscle strengthening and balance components of physical activity guidelines in surveillance, ${ }^{3132}$ or considered the prevalence of meeting these components of guidelines. ${ }^{31}$ Previous evidence suggests that when concurrently considering multiple components of physical activity guidelines, such as muscle strengthening and sedentary behaviour, the population prevalence of 'meeting physical activity guidelines' reduced substantially compared with the prevalence derived based on aerobic MVPA minutes alone. We advocate that components beyond aerobic MVPA minutes be integrated into physical activity surveillance. This implies the value of self-reported physical activity measures in surveillance, despite progress in device-based measures, because specific types of physical activity, such as muscle-strengthening exercise, can only be measured by self-report at the moment.

Furthermore, a comprehensive surveillance system should extend beyond physical activity prevalence to incorporate macrolevel determinants and policy indicators of populationlevel physical activity. ${ }^{83}$ For example, the monitoring framework adopted by the European Union includes a range of thematic areas, such as sports policies and programmes, physical education and public awareness campaigns. ${ }^{34}$ The Global Observatory of Physical Activity ${ }^{35}$ has 146 country members (till December 2018) and includes country-level indicators beyond physical activity prevalence estimates, such as the presence of a national physical activity plan/policy (standalone for physical activity or embedded in an NCD prevention plan), national surveys and research metrics.

Physical activity surveillance plays a central role in identifying the problems and data gaps, benchmarking progress and informing resource prioritisation and policymaking. The field should continue to focus on improving physical activity measurement, incorporating device-based assessment methods, expanding the scope and reach of global surveillance, particularly in low-income and middle-income countries (LMIC), and expanding from unidimensional prevalence surveillance to comprehensive surveillance systems that track multiple aspects of progress.

\section{CORRELATES AND DETERMINANTS}

Identifying the correlates (from cross-sectional studies) and determinants (from longitudinal studies) is important for understanding the causes of physical inactivity and informing activity-promotion strategies. According to the 2012 Lancet series, a plethora of studies had examined the correlates of physical activity at the individual, interpersonal, environmental and policy levels, but fewer studies have examined determinants. ${ }^{36}$ Furthermore, an evidence gap was observed in LMIC. 
An updated review in 2016 found that despite the increasing number of studies, particularly in LMIC, the field is still dominated by cross-sectional studies and the evidence from LMIC is mainly based on studies conducted in Brazil and China. ${ }^{9}$ We conducted another updated search (through March 2019) using the 2016 search protocol and found 40 original studies from LMIC and 11 literature reviews published since 2016 (online supplementary appendix 1-3). The overall pattern of the literature remained unchanged, where $93 \%(\mathrm{n}=37)$ of newly published studies are cross-sectional, $60 \%(n=24)$ of the LMIC studies are from Brazil and China, and no studies from lowincome countries, indicating little change in researchers' practices in this area.

While studies on behavioural correlates and determinants have led to a better understanding of why some people are more active than others, several common issues have limited the usefulness of many studies. ${ }^{36}$ First, although the fundamental rationale for correlate and determinant research is informing interventions, this link has not been made explicit by many studies, and the body of research has evolved to become a stand-alone field, where evidence has seldom been generated with the intended research translation. Second, the body of literature on correlates and determinants of physical activity has been predominantly focused on the individual and interpersonal levels of influence, while making real-world population-level changes requires societal, policy, political and macroeconomic changes. ${ }^{2}$ Third, the field still lacks evidence from studies that apply longitudinal designs, are based on population-representative samples or those that examine behavioural mechanisms. In summary, many correlate studies have been published since 2012. Although the number of studies from LMIC has increased (mainly driven by Brazil and China), the gaps and limitations in the field identified in the 2012 Lancet series remain largely unaddressed, ${ }^{36}$ and journals continue to publish many cross-sectional studies on well-established correlates.

An area of increasing research interest is the environmental correlates of physical activity. For example, of all 40 correlate/ determinant papers from LMIC published since 2016, 11 focused primarily on environmental (particularly built environment) correlates of physical activity. Although longitudinal studies account for less than $5 \%$ of all studies identified through recent literature reviews ${ }^{37-39}$ and 'more longitudinal studies are needed' has been recommended by most studies as a major area of improvement, since 2016, all 11 studies on built environments and physical activity from LMIC have been cross-sectional. To build a stronger evidence base to better inform policy and practice, research on the association between the built environment and physical activity needs to move towards longitudinal designs and to capitalise on opportunities to evaluate 'natural experiments', such as environmental interventions ${ }^{40}$ and residential relocation. ${ }^{41}$ However, such a transformation in the research paradigm needs to be supported by funding agencies' willingness to develop rapid and flexible mechanisms.

In summary, despite the expanding literature on correlates of physical activity, it is uncertain to what degree the growing literature has led to better-informed interventions and policies. Future research should refocus towards a 'solution-oriented' paradigm, by extending knowledge on causes of problems with investigation into how to solve problems like physical inactivity, ${ }^{42}$ with clear alignment between generating knowledge and informing action, and an emphasis on research translation throughout the study. ${ }^{43}$

\section{HEALTH OUTCOMES}

In the past few decades, the research paradigm has been expanded to understand various types and intensities of physical activity and a broadening range of health outcomes, on disease prevention and management, among general and special populations. ${ }^{7}$ Despite the exponential increase in the number of publications, ${ }^{6}$ there are still many areas where more systematic research is needed to improve the evidence base.

Below, we highlight a few research gaps based on US 2018 PAGAC Scientific Report ${ }^{7}$ and the Lancet physical activity series expert group discussion.

\section{The 'optimal' dose of physical activity}

The 2018 PAGAC Scientific Report confirmed the appropriateness of the public health target of 150-300 min per week of MVPA for adults and older adults and $60 \mathrm{~min}$ of MVPA per day for children and adolescents. ${ }^{7}$ However, with continuing technical improvement in and increasing pervasiveness of devicebased measures, we have opportunities to refine the current knowledge on the dose of physical activity, such as frequency, duration and intensity.

Previous studies found a curvilinear dose-response relationship of physical inactivity with coronary heart disease ${ }^{44}$ and mortality outcomes, ${ }^{45} 46$ supporting the statement that 'some physical activity is better than none'. ${ }^{7}$ Future research should continue to improve the understanding of the dose-response relationships between physical activity and other health outcomes, such as different types of cancers and dementia. ${ }^{7}$ Further research on physical activity at extremely low and high levels ${ }^{45} 4748$ will also help to understand the thresholds for the 'minimal' and 'optimal' doses of physical activity associated with health benefits.

To date, the recommended level of physical activity is typically expressed as minutes of activity of a given intensity. Therefore, compared with research on MVPA minutes, there is less evidence on the prospective associations between step counts and health outcomes, such as mortality. A recent investigation from the Women's Health Study found a reduction in mortality rates at as few as around 4400 steps/day, compared with 2700 steps/day and the effects levelled off at around 7500 steps/day, suggesting that the number of steps required for health benefits is smaller than what was commonly perceived..$^{49}$ However, more research is needed to determine the 'optimal' number of steps a day for public health recommendations. Step counts are easy to measure, easy for the general population to understand and could be used to motivate and monitor population behavioural change. Therefore, steps-based evidence may facilitate research translation and implementation. ${ }^{7}$ Further, improvements in objective measures of physical activity also provide opportunities for delineating the health effects of short versus long bouts of physical activity to inform public health messages for increasing incidental physical activity.

Finally, physical activity guidelines commonly define healthenhancing physical activity as MVPA, where 1 min of vigorousintensity activity approximates $2 \mathrm{~min}$ of moderate-intensity activity, based roughly on energy expenditure. Despite vigorousintensity activity being more time-efficient, limited evidence suggests that vigorous-intensity activity may contribute additional benefits. ${ }^{50-53}$ Future studies should compare the roles of vigorous-intensity and moderate-intensity activities, independent of total activity energy expenditure, in disease prevention and management. ${ }^{7}$ This research agenda is particularly timely given the increasing popularity of and promising evidence on highintensity interval training. ${ }^{54}$ On the other end of the spectrum, 
there has been an increasing interest in the health effects of lightintensity physical activity, which can now be better measured with devices. Altogether, understanding the health effects of physical activity on the full spectrum of intensity will help to improve the current knowledge base.

Beyond energy expenditure: the importance of activity domain, type/ mode and component

Physical activity can be accumulated in various domains and the health effects may be domain-specific and outcome-specific. A recent 17-country investigation found both leisure-time and non-leisure-time physical activity to be protective of mortality and cardiovascular disease. ${ }^{55}$ Occupational physical activity has been found to be protective of several NCDs, including some cancers. ${ }^{5657}$ However, a recent meta-analysis reported that more occupational physical activity was linked to a higher risk of allcause mortality, ${ }^{58}$ presenting a potential 'paradox' ${ }^{59}$ This observation has come under some criticism, and it has been suggested that inadequate classification of occupational demands by simple questionnaires and incomplete adjustments for covariates, such as cigarette smoking and socioeconomic status, may explain the 'paradox' ${ }^{60}$ Future research should better account for residual confounding, measure specific aspects of physically demanding jobs, such as musculoskeletal load, psychological distress and worker control, ${ }^{59}$ and investigate the potential mechanisms of the observed association. To date, most research on physical activity has been focused on the leisure-time and transport domains. An improved understanding of occupational and domestic physical activity will help to improve domain-specific evidence to better inform physical activity guidelines, particularly within the context of LMIC where a large proportion of physical activity is not volitional.

Moreover, as physical activity has been commonly quantified by time and intensity only, information pertaining to specific types/modes of physical activity is seldom collected or analysed, and the non-MVPA components of physical activity guidelines, such as muscle-strengthening exercise and balance training, are less studied. ${ }^{31}$ Recent research suggests potential differences in health benefits by type of activity. ${ }^{61-63}$ Future research should aim to understand the role of various types of physical activity on specific physical and mental health outcomes to better inform physical activity recommendations and strategies specific to population subgroups. For example, the PAGAC specifically recommended more research on the effects of balance training and mind-body exercise on brain health, physical functions and the management of chronic conditions. ${ }^{7}$

\section{Physical activity across all stages in life and among those with and without chronic conditions}

To date, the bulk of evidence on physical activity and health is primarily based on studies among apparently healthy adults. Although physical activity-related NCDs are usually manifest in adulthood, risk factors, such as adiposity in childhood, are known to negatively affect health in adults. ${ }^{64}$ Therefore, it is important to better understand the role various aspects of physical activity play in adiposity, cardiometabolic, bone and mental health in childhood, adolescence and the transition into adulthood, during which a dramatic decline in physical activity is often observed. ${ }^{65}$

Physical activity is also considered critical to healthy ageing, not only in terms of preventing NCDs and premature mortality, but also in terms of preventing functional and cognitive declines, ${ }^{66}$ promoting independent mobility and quality of life. ${ }^{6768}$ The PAGAC recommended more research among the older population, particularly regarding multiple components of physical activity among older adults with and without a chronic condition.

Around the world, a large proportion of the population lives with a chronic condition and this proportion increases dramatically with age. ${ }^{69}$ For example, in the USA, around half of the population lives with multiple chronic conditions (80\% among those aged 65 years and above) ${ }^{70}$ Physical activity not only helps to prevent or delay the onset of NCDs, but also aids disease management, with well-documented evidence for reducing depressive symptoms ${ }^{71}$ and managing diabetes, ${ }^{72}$ coronary heart disease ${ }^{73}$ and some cancers. ${ }^{74}$ Recently, the Clinical Oncology Society of Australia recommended physical activity/ exercise to be incorporated into routine cancer care. ${ }^{75}$ Better evidence is still needed on the therapeutic effect of physical activity among people with various conditions, such as cognitive and mental disorders, musculoskeletal problems, specific injuries and disabilities. Future research should particularly focus on comparing the effectiveness of different durations, intensities and types of physical activity as the modality for people living with chronic conditions and disabilities.

\section{The interaction between physical activity and other lifestyle} risk factors

Lifestyle risk factors rarely exist in isolation and may have synergistic effects on health outcomes. ${ }^{76}$ Physical activity may be closely linked to sedentary behaviour (ie, sitting), sleep, diet and adiposity. Emerging evidence suggests that MVPA could offset the health risk associated with excessive time spent in sedentary behaviours ${ }^{77}$; ; future studies should continue to elucidate both independent and joint effects of physical activity and sedentary behaviour on multiple health outcomes. Novel methodologies that take into account the inter-relationships between physical activity and sedentary behaviour and the finite nature of time, such as isotemporal substitution ${ }^{79}$ and compositional data analysis, ${ }^{80}$ are emerging techniques to consider. Understanding the interactions between physical activity and sedentary behaviour is essential to determining whether the observed health effects of sedentary behaviour on health are truly independent of MVPA, ${ }^{81}$ and the amount and intensity of MVPA needed to offset the risk of sedentary behaviour, which, therefore, informs prioritisation of public health resources. Similarly, physical activity may interact with diet, sleep and other health behaviours on the causal pathways to adiposity and chronic conditions, but the current understanding of such interactions is limited and should be improved by future research.

\section{Effect modification by sociodemographic characteristics}

An overarching research gap cited throughout the PAGAC committee report is a lack of knowledge about whether sociodemographic characteristics, such as age, sex, race/ethnicity and socioeconomic status, modify the health effects of physical activity and sedentary behaviour. To date, most evidence on physical activity and sedentary behaviour has been built on studies of predominantly Caucasian populations from high-income countries. Limited data indicate benefits of physical activity across many populations, ${ }^{82}$ suggesting a promising but incomplete evidence base for implementing guidelines and promoting physical activity in all populations. However, to improve the current evidence, more empirical data from non-Caucasian populations and LMIC are needed as these populations may bear higher disease burdens ${ }^{83}$ or experience different disease patterns. ${ }^{84}$ This 
identified research gap reinforces the importance of diversity and equity in scientific research and the need for quality research from LMIC, where people bear the majority of the global disease burden associated with physical inactivity. ${ }^{4}$

\section{INTERVENTIONS, PROGRAMMES AND POLICIES}

The 2012 Lancet series identified a dearth of physical activity intervention studies from LMIC. ${ }^{85}$ The 2016 Lancet series identified more interventions from LMIC, ${ }^{9}$ including social support interventions and physical activity classes in community settings, school-based interventions and community-wide programmes. An updated literature search since 2016 (till March 2019) revealed a continued growth in intervention studies to increase physical activity levels in LMIC, exemplified by at least 68 studies from Brazil, Chile, Colombia, China and Jordan (online supplementary appendix 4-6).

Further, in addition to documenting the health benefits associated with physical activity, the 2018 PAGAC committee report also included a comprehensive review of physical activity promotion strategies, which identified several interventions with demonstrated effectiveness. ${ }^{86}$ These interventions spanned individual, community, communication, physical environment and policy levels. Since 2016, the Community Preventive Services Task Force (CPSTF) has updated a few recommendations for community-level physical activity interventions. Specifically, based on recent systematic reviews, ${ }^{87} 88$ the CPSTF has considered that there is sufficient evidence to recommend familybased interventions for increasing physical activity levels among children $^{89}$ and activity monitor interventions for increasing physical activity among adults who are overweight and obese. ${ }^{90}$ Furthermore, the CPSTF recommends interventions to promote active travel to school (eg, the Safe Routes to School Programs in the USA $)^{91}$ and combining transportation system interventions with land use and environmental design interventions. ${ }^{92}$ It is important to note that all studies that informed these four newly updated recommendations are from high-income countries.

Overall, despite the growing number of physical activity interventions, most published studies continue to focus on individual approaches to behavioural change, and much less research is dedicated to 'upstream' approaches, such as environmental and policy interventions. It has been well-acknowledged that individual behaviours are the result of multilevel influences, with environmental modifications more likely to generate far-reaching, sustainable behavioural change. ${ }^{93}$ Based on comprehensive synthesis of empirical evidence, the Lancet physical activity series has advocated for prioritising environmental over individual approaches for physical activity promotion, and that 'mega-trends', such as important economic, societal, environmental and policy changes, have profound impacts on population health and offer opportunities for mobilising populations for positive changes. ${ }^{94}$ These approaches are in line with GAPPA's policy recommendations. ${ }^{8}$ As a working group, we have also recommended the evaluation of scaled-up physical activity interventions through multisectoral, multidisciplinary responses, ${ }^{43}$ such as Academia da Saúde ${ }^{95}$ and Academia das Cidades. ${ }^{96}$ Since our call for action, there has been some promising progress in the field with more at-scale
- Focusing on implementation

- Practice-based opportunities and experiences

- Working across disciplines and sectors to maximise'cobenefits'

\section{- Device-based assessments to complement survey measures \\ - Comprehensivesurveillance systems to incorporate macrolevel determinants and policy indicators}

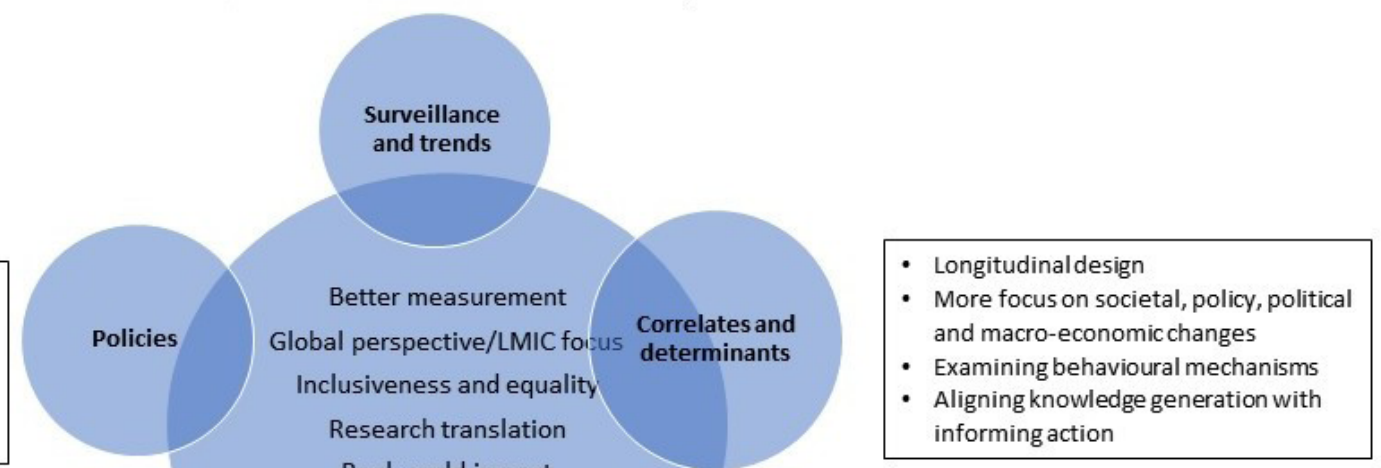

Figure 1 Recommendations for future physical activity research. LMIC, low-income and middle-income countries PA, physical activity. 
interventions evaluated, ${ }^{97-100}$ and new frameworks for evaluation and implementation proposed. ${ }^{101}$

The mismatch between research priorities and current research practice may be partially caused by the funding and academic reward systems. The research agenda has been largely driven by what can be measured and changed easily, rather than what should be measured and changed for population health. Funding bodies tend to be risk-averse and inflexible in terms of budgets and timelines, which poses challenges to comprehensive community-wide programmes and environmental interventions, where multiple sectors need to be engaged and researchers do not have full control over the progress and timing of the interventions. ${ }^{102} 103$ However, there are some promising examples of research funding specifically targeting evaluations of naturally occurring policies and programmes (eg, National Institutes of Health obesity policy Requests for Applications/RFA). Furthermore, community-wide, multilevel, cross-sectoral interventions are complex in nature, and difficult and time-consuming to implement and evaluate (eg, timing and other logistic challenges, disentangling effects of components when evaluating multicomponent interventions), and possibly less 'efficient' in terms of opportunities for traditional academic outputs. Therefore, researchers may be disincentivised to pursue intervention studies that may truly make a difference in the long term.

Future physical activity interventions and programmes should move away from repeating what is already known and from adopting strategies that are less likely to lead to sustainable population-level behaviour change. Instead, researchers should prioritise implementing evidence-based interventions, such as the seven best investments for physical activity, ${ }^{104}$ incorporating practice-based opportunities and experiences, applying effective strategies for risk communication and evidence dissemination, working across disciplines and sectors to scale-up impacts, ${ }^{43}$ and understanding the determinants of and variability in populationlevel uptake of physical activity promotion strategies. Translation should be made a research priority and be included in every aspect of research from design to evaluation. Economic evaluation $^{105} 106$ and co-benefit analysis ${ }^{107}$ should be encouraged as a standard practice to facilitate decision-making in a resourceconstrained world. Finally, more research should be conducted among inactive and vulnerable population subgroups, such as those with disabilities, to ensure equity and inclusiveness in physical activity promotion.

\section{SUMMARY}

In this article, we summarised the lessons we learnt from the 2012 and 2016 Lancet physical activity series and other major developments on various aspects of physical activity research. We identified knowledge gaps and provided suggestions for future research based on literature reviews, expert consultation and panel discussion. The lessons we shared are by no means comprehensive, but we hope that they contribute to moving the field forward towards achieving population-level impact globally.

In the last few decades, the field of physical activity research has grown exponentially in all areas, with health outcome research being at a more developed stage than others. ${ }^{6}$ All areas: surveillance and trends, correlates and determinants, health outcomes, interventions and policies, interconnect, building on each other to provide a complete picture to understand and tackle the pandemic of physical inactivity. We have summarised the lessons we have learnt from the development of each area in figure 1. Some lessons and suggestions are shared across the areas and may be considered as part of the 'roadmap' for future research in the field of physical activity. We consider improvements in measurement as the foundation for all areas of physical activity research. We advocate for an 'upstream' public health approach to extend research from describing problems to providing solutions, and to connect knowledge generation with research translation. Physical inactivity is a 'wicked problem'108 that requires a systems-based approach instead of a single quick fix. ${ }^{8}$ Researchers and stakeholders need to work across disciplines and sectors to co-design research and co-create solutions. Although each jurisdiction faces unique situations, a global perspective to understand and modify the macrolevel drivers of the pandemic and a focus on LMIC and disadvantaged populations are essential to ensure that every individual and population has the opportunity and right to move in a supportive and safe environment and reap the benefits of physical activity.

\section{What is already known}

- The research field of physical activity has been expanding. Progress has been observed in global physical activity surveillance, research on the health consequences, and correlates and determinants of physical inactivity, interventions, translation and policy.

- The Lancet physical activity series, published in 2012 and 2016, include comprehensive global analysis on physical activity and have generated far-reach impacts in terms of citations, media coverage and global advocacy.

- Other major recent developments, such as the 2018 Physical Activity Guidelines for Americans and WHO Global Action Plan for Physical Activity, provide key scientific evidence and policy direction for physical activity promotion.

\section{What are the new findings}

- Surveillance: more and more countries collect physical activity surveillance data. Future surveillance should expand the use of device-based measures in combination with self-report and incorporate policy indicators.

- Correlates and determinants: research continues to be dominated by cross-sectional studies without explicit links to informing interventions. Future research should focus on macrolevel determinants, examine behavioural mechanisms and align knowledge generation with informing action.

- Health outcomes: knowledge has accumulated on a broadening range of health outcomes. Future research should continue to understand the 'optimal dose' of physical activity and build evidence on effects of domain, type, intensity and components of physical activity on various health outcomes across different life stages.

- Interventions, programmes and policy: most published studies continue to focus on individual approaches to behavioural change. Future endeavour should prioritise implementing evidence-based interventions, incorporate practice-based opportunities and experiences, work across disciplines and sectors, scale-up impacts and make translation a research priority.

- Across all areas, we recommend that physical activity research should be based on improved measurement and interdisciplinary and cross-sectoral collaboration, apply a global perspective and principles of inclusiveness and equity, and focus on research translation for real-world impact. 


\section{Author affiliations}

Prevention Research Collaboration, Sydney School of Public Health, The University of Sydney, Camperdown, New South Wales, Australia

${ }^{2}$ Charles Perkins Centre, The University of Sydney, Camperdown, New South Wales, Australia

${ }^{3}$ Faculty of Medicine, Universidad de los Andes, Bogota, Colombia

${ }^{4}$ Department of Sport Medicine, Norwegian School of Sport Sciences, Oslo, Norway

${ }^{5}$ Division of Preventive Medicine, Brigham and Women's Hospital, Harvard Medical

School, Boston, Massachusetts, USA

${ }^{6}$ Department of Epidemiology, Harvard TH Chan School of Public Health, Boston,

Massachusetts, USA

${ }^{7}$ The Department of Health \& Human Performance, University of Tennessee at

Chattanooga, Chattanooga, Tennessee, USA

${ }^{8}$ Pennington Biomedical Research Center, Baton Rouge, Louisiana, USA

${ }^{9}$ Research Group in Physical Actvity and Quality of Life (GPAQ), Pontifícia

Universidade Católica do Paraná, Curitiba, Curitiba, Brazil

${ }^{10}$ Postgraduate Program in Urban Management (PPGTU), Pontifícia Universidade

Católica do Paraná, Curitiba, Brazil

${ }^{11}$ Institute for Public Health, Department of Family Medicine and Public Health,

University of California San Diego, La Jolla, California, USA

Acknowledgements The public lectures and expert group meetings 'Learning from the Lancet: lessons and future research directions drawn from the 2012 and 2016 global series on physical activity and health' were funded by the National Institutes of Health (NIH R13 CA228499-01). The authors wish to thank the presenters at the 'Learning from the Lancet' lecturers (AEB, Bess Marcus, Harold Kohl, Charlie Foster, Deborah Salvo, DD, Elena Martinez, GH, I-ML, Jacqueline Kerr, James Sallis, Job Godino, Kevin Patrick, MP, Noe Crespo, PTK, Robert Haile, RR, Ross Brownson, Russ Pate and UE) and the attendees of the expert group meetings (Alma Behar, Andrea Mendozavasconez, ARV, Celina H Shirazipour, Claudia Aranda Vanegas, Katie Crist, Lorena S Pacheco, Maryam Gholami, Melawhy Garcia, Natalicio Serrano, Priscilla Vazquez, Rosa Alicia Avila Avalos and Sharon Thompson) for their input.

Contributors DD drafted the manuscript based on discussions involving all the authors, and literature reviews were conducted by ARV. All the authors have critically reviewed the draft and approved the final version before submission.

Funding This study was supported by the National Heart Foundation of Australia (101234) and the National Institutes of Health (NIH R13 CA228499-01). DD was funded by a Future Leader Fellowship from the Australian Heart Foundation (\#101234) and a University of Sydney SOAR fellowship.

Competing interests None declared.

Patient consent for publication Not required.

Provenance and peer review Not commissioned; externally peer reviewed.

Open access This is an open access article distributed in accordance with the Creative Commons Attribution Non Commercial (CC BY-NC 4.0) license, which permits others to distribute, remix, adapt, build upon this work non-commercially, and license their derivative works on different terms, provided the original work is properly cited, appropriate credit is given, any changes made indicated, and the use is non-commercial. See: http://creativecommons.org/licenses/by-nc/4.0/.

\section{ORCID iDs}

Ding Ding http://orcid.org/0000-0001-9850-9224

Michael Pratt http://orcid.org/0000-0002-8939-7715

\section{REFERENCES}

1 Guthold R, Stevens GA, Riley LM, et al. Worldwide trends in insufficient physical activity from 2001 to 2016: a pooled analysis of 358 population-based surveys with 1.9 million participants. Lancet Glob Health 2018;6:e1077-86.

2 Kohl HW, Craig CL, Lambert EV, et al. The pandemic of physical inactivity: global action for public health. The Lancet 2012;380:294-305.

3 Lee I-M, Shiroma EJ, Lobelo F, et al. Effect of physical inactivity on major noncommunicable diseases worldwide: an analysis of burden of disease and life expectancy. The Lancet 2012;380:219-29.

4 Ding $\mathrm{D}$, Lawson KD, Kolbe-Alexander TL, et al. The economic burden of physical inactivity: a global analysis of major non-communicable diseases. The Lancet 2016:388:1311-24

5 Morris JN, Heady JA, Raffle PAB, et al. Coronary heart-disease and physical activity of work. The Lancet 1953;262:1111-20.

6 Varela AR, Pratt M, Harris J, et al. Mapping the historical development of physical activity and health research: a structured literature review and citation network analysis. Prev Med 2018;111:466-72.

7 Physical activity guidelines Advisory Committee. 2018 physical activity guidelines Advisory Committee scientific report. Washington, DC: U.S. Department of Health and Human Services, 2018
8 World Health Organization. Global action plan on physical activity 2018-2030: more active people for a healthier world. Geneva World Health Organization; 2018. http:// www.who.int/ncds/prevention/physical-activity/gappa/action-plan

9 Sallis JF, Bull F, Guthold R, et al. Progress in physical activity over the Olympic quadrennium. The Lancet 2016;388:1325-36.

10 Hallal PC, Andersen LB, Bull FC, et al. Global physical activity levels: surveillance progress, pitfalls, and prospects. Lancet 2012;380:247-57.

11 Craig CL, Marshall AL, Sjöström M, et al. International physical activity questionnaire: 12-country reliability and validity. Med Sci Sports Exerc 2003;35:1381-95.

12 Bull FC, Maslin TS, Armstrong T. Global physical activity questionnaire (GPAQ): nine country reliability and validity study. J Phys Act Health 2009;6:790-804.

13 Pate RR, Pratt M, Blair SN, et al. Physical activity and public health. A recommendation from the centers for disease control and prevention and the American College of sports medicine. JAMA 1995;273:402-7

14 World Health Organization. Global recommendations on physical activity for health. Geneva: Switzerland World Health Organization, 2010.

15 Sallis JF, Saelens BE. Assessment of physical activity by self-report: status, limitations, and future directions. Res Q Exerc Sport 2000;71 Suppl 2:1-14.

16 Troiano RP, Berrigan D, Dodd KW, et al. Physical activity in the United States measured by accelerometer. Med Sci Sports Exerc 2008;40:181-8.

17 Steene-Johannessen J, Anderssen SA, van der Ploeg HP, et al. Are self-report measures able to define individuals as physically active or inactive? Med Sci Sports Exerc 2016:48:235-44.

18 Colley RC, Garriguet D, Janssen I, et al. Physical activity of Canadian children and youth: accelerometer results from the 2007 to 2009 Canadian health measures survey. Health Rep 2011;22:15-23.

19 Loyen A, Clarke-Cornwell AM, Anderssen SA, et al. Sedentary time and physical activity surveillance through Accelerometer pooling in four European countries. Sports Med 2017;47:1421-35.

20 Hagströmer M, Troiano RP, Sjöström M, et al. Levels and patterns of objectively assessed physical activity-a comparison between Sweden and the United States. Am J Epidemiol 2010;171:1055-64

21 Fisberg M, Kovalskys I, Gómez G, et al. Latin American study of nutrition and health (ELANS): rationale and study design. BMC Public Health 2015;16:93.

22 Sallis JF, Cerin $\mathrm{E}$, Conway TL, et al. Physical activity in relation to urban environments in 14 cities worldwide: a cross-sectional study. Lancet 2016;387:2207-17.

23 Wijndaele K, Westgate K, Stephens SK, et al. Utilization and harmonization of adult Accelerometry data: review and expert consensus. Med Sci Sports Exerc 2015:47:2129-39.

24 Althoff T, Sosič R, Hicks JL, et al. Large-scale physical activity data reveal worldwide activity inequality. Nature 2017:547:336-9.

25 Poushter J. Smartphone ownership and Internet usage continues to climb in emerging economies: Pew research center, 2016. Available: http://www.pewglobal org/2016/02/22/smartphone-ownership-and-internet-usage-continues-to-climb-inemerging-economies/ [Accessed 13 Aug 2018].

26 Hekler EB, Buman MP, Grieco L, et al. Validation of physical activity tracking via android Smartphones compared to ActiGraph Accelerometer: laboratory-based and free-living validation studies. JMIR Mhealth Uhealth 2015:3:e36.

27 Nolan M, Mitchell JR, Doyle-Baker PK. Validity of the apple iPhone $® /$ iPod Touch $®$ as an accelerometer-based physical activity monitor: a proof-of-concept study. J Phys Act Health 2014;11:759-69.

28 Amagasa S, Kamada M, Sasai H, et al. How well iPhones measure steps in free-living conditions: cross-sectional validation study. JMIR Mhealth Uhealth 2019;7:e10418.

29 Ostherr K, Borodina S, Bracken RC, et al. Trust and privacy in the context of usergenerated health data. Big Data Soc 2017;4.

30 Bagot KS, Matthews SA, Mason M, et al. Current, future and potential use of mobile and wearable technologies and social media data in the ABCD study to increase understanding of contributors to child health. Dev Cogn Neurosci 2018;32:121-9.

31 Milton K, Varela AR, Strain T, et al. A review of global surveillance on the muscle strengthening and balance elements of physical activity recommendations. Journal of Frailty, Sarcopenia and Falls 2018;03:114-24.

32 Katzmarzyk PT, Lee I-M, Martin CK, et al. Epidemiology of physical activity and exercise training in the United States. Prog Cardiovasc Dis 2017;60:3-10.

33 Ding D. Surveillance of global physical activity: progress, evidence, and future directions. Lancet Glob Health 2018;6:e1046-7.

34 Breda J, Jakovljevic J, Rathmes $\mathrm{G}$, et al. Promoting health-enhancing physical activity in Europe: current state of surveillance, policy development and implementation. Health Policy 2018;122:519-27.

35 Hallal PC, Martins RC, Ramírez A. The Lancet physical activity Observatory: promoting physical activity worldwide. Lancet 2014;384:471-2.

36 Bauman AE, Reis RS, Sallis JF, et al. Correlates of physical activity: why are some people physically active and others not? Lancet 2012;380:258-71.

37 Barnett DW, Barnett A, Nathan A, et al. Built environmental correlates of older adults' total physical activity and walking: a systematic review and meta-analysis. Int J Behav Nutr Phys Act 2017:14

38 Cerin E, Nathan A, van Cauwenberg J, et al. The neighbourhood physical environment and active travel in older adults: a systematic review and meta-analysis. Int J Behav Nutr Phys Act 2017;14. 
39 da Silva IC, Payne VL, Hino AA, et al. Physical activity and safety from crime among adults: a systematic review. J Phys Act Health 2016;13:663-70.

40 Panter J, Guell C, Prins R, et al. Physical activity and the environment: conceptual review and framework for intervention research. Int I Behav Nutr Phys Act 2017;14.

41 Ding D, Nguyen B, Learnihan V, et al. Moving to an active lifestyle? A systematic review of the effects of residential relocation on walking, physical activity and travel behaviour. Br J Sports Med 2018;52:789-99.

42 Robinson TN, Sirard JR. Preventing childhood obesity: a solution-oriented research paradigm. Am J Prev Med 2005;28(2 Suppl 2):194-201.

43 Reis RS, Salvo D, Ogilvie D, et al. Scaling up physical activity interventions worldwide: stepping up to larger and smarter approaches to get people moving. The Lancet 2016;388:1337-48

44 Sattelmair J, Pertman J, Ding EL, et al. Dose response between physical activity and risk of coronary heart disease: a meta-analysis. Circulation 2011;124:789-95.

45 Arem H, Moore SC, Patel A, et al. Leisure time physical activity and mortality: a detailed pooled analysis of the dose-response relationship. JAMA Intern Med 2015;175:959-67.

46 Ekelund U, Tarp J, Steene-Johannessen J, et al. Dose-response associations between accelerometry measured physical activity and sedentary time and all cause mortality: systematic review and harmonised meta-analysis. BMJ 2019;366.

47 Paffenbarger RS, Hyde RT, Wing AL, et al. Physical activity, all-cause mortality, and longevity of college alumni. N Eng/ J Med 1986;314:605-13.

48 Aengevaeren VL, Mosterd A, Braber TL, et al. Relationship between lifelong exercise volume and coronary atherosclerosis in athletes. Circulation 2017:136:138-48.

49 Lee IM, Shiroma EJ, Kamada M, et al. Association of step volume and intensity with all-cause mortality in older women. JAMA Intern Med 2019.

50 Liubaoerjijin Y, Terada T, Fletcher K, et al. Effect of aerobic exercise intensity on glycemic control in type 2 diabetes: a meta-analysis of head-to-head randomized trials. Acta Diabetol 2016;53:769-81.

51 Gebel K, Ding D, Bauman AE. Volume and intensity of physical activity in a large population-based cohort of middle-aged and older Australians: prospective relationships with weight gain, and physical function. Prev Med 2014;60:131-3.

52 Gebel K, Ding D, Chey T, et al. Effect of moderate to vigorous physical activity on all-cause mortality in middle-aged and older Australians. JAMA Intern Med 2015:175:970-7.

53 Shiroma EJ, Sesso HD, Moorthy MV, et al. Do moderate-intensity and vigorousintensity physical activities reduce mortality rates to the same extent? J Am Heart Assoc 2014;3:e000802.

54 Batacan RB, Duncan MJ, Dalbo VJ, et al. Effects of high-intensity interval training on cardiometabolic health: a systematic review and meta-analysis of intervention studies. Br J Sports Med 2017:51:494-503.

55 Lear SA, Hu W, Rangarajan S, et al. The effect of physical activity on mortality and cardiovascular disease in 130000 people from 17 high-income, middle-income, and low-income countries: the PURE study. Lancet 2017;390:2643-54.

56 Moore SC, Gierach GL, Schatzkin A, et al. Physical activity, sedentary behaviours, and the prevention of endometrial cancer. Br J Cancer 2010;103:933-8.

57 Liu Y, Hu F, Li D, et al. Does physical activity reduce the risk of prostate cancer? A systematic review and meta-analysis. Eur Urol 2011;60:1029-44.

58 Coenen P, Huysmans MA, Holtermann A, et al. Do highly physically active workers die early? A systematic review with meta-analysis of data from 193696 participants. Br J Sports Med 2018;52:1320-6.

59 Holtermann A, Krause N, van der Beek AJ, et al. The physical activity paradox: six reasons why occupational physical activity (opa) does not confer the cardiovascular health benefits that leisure time physical activity does. Br J Sports Med 2018;52:149-50.

60 Shephard RJ. Is there a 'recent occupational paradox' where highly active physically active workers die early? Or are there failures in some study methods? Br I Sports Med 2019:bjsports-2018-100344

61 Oja P, Kelly P, Pedisic Z, et al. Associations of specific types of sports and exercise with all-cause and cardiovascular-disease mortality: a cohort study of 80306 British adults. Br J Sports Med 2017;51:812-7.

62 Merom D, Ding D, Stamatakis E. Dancing participation and cardiovascular disease mortality: a pooled analysis of 11 population-based British cohorts. Am J Prev Med 2016;50:756-60.

63 Stamatakis E, Lee I-M, Bennie J, et al. Does strength-promoting exercise confer unique health benefits? A pooled analysis of data on 11 population cohorts with all-cause, cancer, and cardiovascular mortality endpoints. Am J Epidemiol 2018:187:1102-12

64 Reilly JJ, Kelly J. Long-Term impact of overweight and obesity in childhood and adolescence on morbidity and premature mortality in adulthood: systematic review. Int J Obes 2011;35:891-8.

65 Dumith SC, Gigante DP, Domingues MR, et al. Physical activity change during adolescence: a systematic review and a pooled analysis. Int J Epidemiol 2011;40:685-98

66 Sofi F, Valecchi D, Bacci D, et al. Physical activity and risk of cognitive decline: a meta-analysis of prospective studies. J Intern Med 2011;269:107-17.
67 Pahor M, Guralnik JM, Ambrosius WT, et al. Effect of structured physical activity on prevention of major mobility disability in older adults: the life study randomized clinical trial. JAMA 2014;311:2387-96

68 Kelley GA, Kelley KS, Hootman JM, et al. Exercise and health-related quality of life in older community-dwelling adults: a meta-analysis of randomized controlled trials. $J$ Appl Gerontol 2009;28:369-94.

69 Hajat C, Stein E. The global burden of multiple chronic conditions: a narrative review. Prev Med Rep 2018:12:284-93

70 Gerteis JID, Deitz D, LeRoy L, et al. Multiple chronic conditions chartbook. AHRQ publications NO, Q14-0038. Rockville, MD: Agency for Healthcare Research and Quality, 2014

71 Josefsson T, Lindwall M, Archer T. Physical exercise intervention in depressive disorders: meta-analysis and systematic review. Scand I Med Sci Sports 2014;24:259-72

72 Kodama S, Tanaka S, Heianza Y, et al. Association between physical activity and risk of all-cause mortality and cardiovascular disease in patients with diabetes: a metaanalysis. Diabetes Care 2013:36:471-9.

73 Anderson L, Thompson DR, Oldridge N, et al. Exercise-based cardiac rehabilitation for coronary heart disease. Cochrane Database Syst Rev 2016;(1):CD001800.

74 Friedenreich CM, Neilson HK, Farris MS, et al. Physical activity and cancer outcomes: a precision medicine approach. Clin Cancer Res 2016;22:4766-75.

75 Clinical Oncology Society of Australia (COSA). Position statement on exercise in cancer care 2018.

76 Ding D, Rogers K, van der Ploeg H, et al. Traditional and emerging lifestyle risk behaviors and all-cause mortality in middle-aged and older adults: evidence from a large population-based Australian cohort. PLoS Med 2015;12:e1001917.

77 Ekelund U, Steene-Johannessen J, Brown WJ, et al. Does physical activity attenuate, or even eliminate, the detrimental association of sitting time with mortality? A harmonised meta-analysis of data from more than 1 million men and women. The Lancet 2016:388:1302-10.

78 Ekelund U, Brown WJ, Steene-Johannessen J, et al. Do the associations of sedentary behaviour with cardiovascular disease mortality and cancer mortality differ by physical activity level? A systematic review and harmonised meta-analysis of data from 850060 participants. Br J Sports Med 2019;53:886-94.

79 Stamatakis E, Rogers K, Ding D, et al. All-Cause mortality effects of replacing sedentary time with physical activity and sleeping using an isotemporal substitution model: a prospective study of 201,129 mid-aged and older adults. Int J Behav Nutr Phys Act 2015;12.

80 Chastin SFM, Palarea-Albaladejo J, Dontje ML, et al. Combined effects of time spent in physical activity, sedentary behaviors and sleep on obesity and CardioMetabolic health markers: a novel compositional data analysis approach. PLoS One 2015:10:e0139984.

81 Stamatakis E, Ekelund U, Ding D, et al. Is the time right for quantitative public health guidelines on sitting? A narrative review of sedentary behaviour research paradigms and findings. Br J Sports Med 2019;53:377-82.

82 Milton K, Macniven R, Bauman A. Review of the epidemiological evidence for physical activity and health from low- and middle-income countries. Glob Public Health 2014:9:369-81.

83 Ooi SL, Martinez ME, Li Cl. Disparities in breast cancer characteristics and outcomes by race/ethnicity. Breast Cancer Res Treat 2011;127:729-38.

84 Jin K, Ding D, Gullick J, et al. A Chinese immigrant paradox? Low coronary heart disease incidence but higher short-term mortality in Western-Dwelling Chinese immigrants: a systematic review and meta-analysis. J Am Heart Assoc 2015;4.

85 Heath GW, Parra DC, Sarmiento OL, et al. Evidence-based intervention in physical activity: lessons from around the world. The Lancet 2012:380:272-81.

86 Powell KE, King AC, Buchner DM, et al. The scientific foundation for the physical activity quidelines for Americans, 2nd edition. J Phys Act Health:16:1-11.

87 Brown HE, Atkin AJ, Panter J, et al. Family-based interventions to increase physical activity in children: a systematic review, meta-analysis and realist synthesis. Obesity Reviews 2016;17:345-60.

88 de Vries HJ, Kooiman TJM, van Ittersum MW, et al. Do activity monitors increase physical activity in adults with overweight or obesity? A systematic review and metaanalysis. Obesity 2016;24:2078-91.

89 The Community Preventive Services Task Force (CPSTF). Physical activity: familybased interventions: CPSTF; 2016

90 The Community Preventive Services Task Force (CPSTF). Physical activity: interventions including activity monitors for adults with overweight or obesity; 2017

91 The Community Preventive Services Task Force (CPSTF). Physical activity: interventions to increase active travel to school; 2018.

92 The Community Preventive Services Task Force (CPSTF). Physical activity: built environment approaches combining transportation system interventions with land use and environmental design: CPSTF; 2016.

93 Sallis JF, Owen N, Fisher EB. Ecological models of health behavior. In: Glanz K, Rimer $\mathrm{BK}$, Viswanath $\mathrm{K}$, eds. Health behavior and health education: theory, research, and practice. 4th edition. San Francisco: Jossey-Bass, 2008

94 Pratt $\mathrm{M}$, Sarmiento OL, Montes $\mathrm{F}$, et al. The implications of megatrends in information and communication technology and transportation for changes in global physical activity. Lancet 2012;380:282-93 
95 Parra DC, Hoehner CM, Hallal PC, et al. Scaling up of physical activity interventions in Brazil: how partnerships and research evidence contributed to policy action. Glob Health Promot 2013;20:5-12.

96 Simões EJ, Hallal PC, Siqueira FV, et al. Effectiveness of a scaled up physical activity intervention in Brazil: a natural experiment. Prev Med 2017;103:S66-72.

97 Sutherland RL, Nathan NK, Lubans DR, et al. An RCT to facilitate implementation of school practices known to increase physical activity. Am J Prev Med 2017;53:818-28.

98 Torres A, Díaz MP, Hayat MJ, et al. Assessing the effect of physical activity classes in public spaces on leisure-time physical activity: "Al Ritmo de las Comunidades" A natural experiment in Bogota, Colombia. Prev Med 2017;103:S51-8.

99 Knell G, Durand CP, Shuval K, et al. Transit use and physical activity: findings from the Houston travel-related activity in neighborhoods (train) study. Prev Med Rep 2018:9:55-61.

100 McKay H, Nettlefold L, Bauman A, et al. Implementation of a co-designed physical activity program for older adults: positive impact when delivered at scale. BMC Public Health 2018;18:1289.

101 Koorts H, Eakin E, Estabrooks P, et al. Implementation and scale up of population physical activity interventions for clinical and community settings: the PRACTIS guide. Int J Behav Nutr Phys Act 2018;15.
102 Lawlor DAet al. The challenges of evaluating environmental interventions to increase population levels of physical activity: the case of the UK national cycle network. J Epidemiol Community Health 2003;57:96-101.

103 Ogilvie D, Mitchell R, Mutrie N, et al. Evaluating health effects of transport interventions methodologic case study. Am J Prev Med 2006;31:118-26.

104 Trost SG, Blair SN, Khan KM. Physical inactivity remains the greatest public health problem of the 21 st century: evidence, improved methods and solutions using the '7 investments that work' as a framework. $\mathrm{Br} J$ Sports Med 2014;48:169-70.

105 Abu-Omar K, Rütten A, Burlacu I, et al. The cost-effectiveness of physical activity interventions: a systematic review of reviews. Prev Med Rep 2017:8:72-8.

106 Ding D, Kolbe-Alexander T, Nguyen B, et al. The economic burden of physical inactivity: a systematic review and critical appraisal. Br J Sports Med 2017;51:1392-409.

107 Sallis JF, Spoon C, Cavill N, et al. Co-benefits of designing communities for active living: an exploration of literature. Int J Behav Nutr Phys Act 2015;12.

108 Peters BG. What is so wicked about wicked problems? A conceptual analysis and a research program. Policy and Society 2017;36:385-96. 